\title{
Performance Evaluation of Engineering Teachers in Universities Based AHP Method
}

\author{
Xingfeng Liü, a, Shuai Liü, b and Tiansong Zhou ${ }^{1, c}$ \\ ${ }^{1}$ School of Management, Wuhan University of Technology, P. R. China, 430070 \\ a249763651@qq.com, b445311943@qq.com, '346822862@qq.com
}

Keywords: Engineering teachers in universities; Performance evaluation; AHP

\begin{abstract}
As an important part of human resource management, performance evaluation of engineering teachers is an important influent factor of the successful implementation of the "Plan for Educating and Training Outstanding Engineers"(PETOE), which is the "Long-term Education Reform and Development Plan"(2010-2020) of the major reform of Chinese higher education programs. On the basis of competency theory of iceberg model, four aspects of quality, knowledge, teaching and scientific research ability as well as personal feature are emphasized to establish performance framework. Furthermore, analytic hierarchy process (AHP) method is applied to determine the index weight to make the performance evaluation more scientific and rational.
\end{abstract}

\section{Introduction}

"Plan for Educating and Training Outstanding Engineers" (hereinafter referred to as PETOE) is the "Medium-long-term Education Reform and Development Plan" (2010 - 2020) of the major reform of Chinese higher education programs proposed by Chinese Ministry of Education. There are currently 194 colleges and universities participating in the PETOE and considerable progress has been made at present. As an important management method to stimulate the driving force of creativity and enthusiasm of engineering teachers, the feasibility and rationality of performance evaluation of engineering teachers are of great significance to strengthen the construction of engineering teachers [1]

Iceberg model theory was put forward by the famous American psychologist McClelland in 1973 [2]. According to the different manifestation of the individual, professor McClelland classified the iceberg into two parts, one is superficial "part of the iceberg above the surface" and the other is deep "part of iceberg below the surface". The "part of the iceberg above the surface" including knowledges and skills are the external manifestation which can be easily understood and measured, thus they are relatively easy to change through training and development. The "part of the iceberg below the surface" including social roles, self-image, feature and motivation are internal manifestation and difficult to be measured. Although this part is less likely to be influenced and changed by the surroundings, it plays a crucial role in people's behavior and performance. McClelland thinks that tests of traditional intelligence and aptitude cannot predict people's professional success and other important achievements [3]. He advocates that individual conditions and real behavioral characteristics which are called the competency affect job performance. Many researchers believe that the competency model is becoming an important part of human resource management, so the modern enterprise management should use competency evaluation to predict job performance [4-5].

Western studies of performance evaluation of teachers in universities have started earlier. Representative methodologies are as follows: balanced score card, statistical analysis, Markov chain method, analytic hierarchy process (AHP), comprehensive evaluation method, management by objectives, key performance indicators and so on [6-8]. Chinese scholars have been continually improving and complementing models, methods and techniques of evaluation performance on the foundation of the experiences and results of western studies. Scholars such as Wang Qiong (2005), Qin Liang-sheng[9] (2007) and Zhang Sheng(2009) have used the method of 360-degree feedback on the performance evaluation of teachers, putting forward relevant evaluation criteria, procedures 
and implementing strategies. Guo Cai-qin [10](2006), Xu Ji-hong (2007) and Cao Guo-liang (2012) have studied programs, models and management of the performance evaluation of the teachers based on balanced score card in universities. Xu Cheng-peng [11] (2007) has used the analytic hierarchy process (AHP) and fuzzy mathematics method to determine the index weight to establish evaluation model. Zhu Cui-miao [12] (2007) has analyzed the cases in universities by the means of rough set theory and distinguished matrix to explore the rules of performance evaluation and obtain objective weight of evaluating factor. Chen Shao-hui [13] (2012) has made empirical analysis on the performance evaluation of teachers, suggesting the index of performance evaluation should be designed from developing strategies in universities. Su Ning-hong [14] (2007) has applied AHP to performance evaluation of teachers to determine the weight and build the right index of evaluation system.

In summary, there are some achievements on the research methods of the current performance evaluation of teachers in universities at home and abroad. However, researches on the evaluation performance of the engineering teachers by means of AHP combining competency theory of iceberg model in universities are rarely few. Many universities in PETOE haven't established scientific system of performance evaluation in accordance with the characteristics and job requirements of engineering teachers. Performance evaluation of engineering teachers has become an important breakthrough in human resources management in universities.

Therefore, this paper attempts to apply the popular analytic hierarchy process (AHP) into performance evaluation of engineering teachers with the theory of iceberg model to improve the reliability and operability of the appraisal process of engineering teachers. In terms of analytic hierarchy process (AHP), which is proposed by American operational research expert T.L. Saaty in the early 1970s, is a decision-analysis method of hierarchical weight that divides relevant factors down into levels of goals, guidelines, programs and others. On the basis of these levels, qualitative and quantitative analysis is made [15]. Since people often encounter multi-index and comprehensive multi-program comparison problem, the selection of the best combination of solutions from hundreds of indicators and programs has become a troublesome problem [16]. In practical application, although people cannot solve the problem of comprehensive comparison of multiple programs, it's easier for them to compare between two programs. And basic idea of AHP is to try to find a mathematical way to make the transition from the multi-program comparison to double-comparison to solve the problem of multi-program comparison [17].

\section{Case of Performance Evaluation of AHP of Engineering Teachers in Universities}

Establishment of Performance Evaluation System of Engineering Teachers. At present, there are a number of factors of the performance evaluation of engineering teachers in universities as the structure is complicated. According to the characteristics of the work of engineering teachers in universities and the competency model of iceberg theory proposed by Spencer, this paper establishes hierarchical structure(see Fig. 1) from four aspects of qualities, knowledges, teaching and scientific research ability and personal qualities as well. The uppermost layer is called the target layer which is a predetermined objective to analyze the problem. The intermediate layer is called criterion layer or index layer and the lowermost layer is called the scheme layer or object layer. Structure of performance evaluation of engineering teachers is as follows: The structure of quality refers the qualification which is engaged in the engineering profession for the engineering teachers to complete engineering education work. The structure of knowledge is internal situation of knowledge in the individual mind, including the number of units of knowledge, quality, category and their interconnections. The structure of teaching and research ability is the sum of basic skills and teaching and scientific research abilities of engineering teachers. The structure of personal feature or trait is the unique character qualities of engineering teachers on the basis of long-term accumulation and the impact of the external environment and education.

This paper is to use SPSS19.0 to make reliability analysis (reliability statistics) for the sample questionnaires and the results are shown in Table 1. From the results, we find the two coefficients are both more than $90 \%$, so there are high internal consistency and strong reliability for the 
questionnaires which can be analyzed in depth.

Table 1 Reliability analysis of the questionnaire of the importance of competency's elements of engineering teachers in universities

\begin{tabular}{|c|c|c|}
\hline cronbach's Alpha & cronbach's alpha based on standardized items & N of items \\
\hline .936 & .964 & 24 \\
\hline
\end{tabular}

Establishment of Judgment Matrix. Judgment matrix is an important basis for the calculation of relative importance. We assume that the target layer of " $U$ " has the dominant relationship for the object layer $U_{1}, U_{2}, U_{3}$ and $U_{4}$. For the target layer $U$, the importance of $U_{i}$ and $U_{j}$ needs to be compared and determined, and the "importance" needs to be given certain value. For the 4 index elements of the indicators, pairwise comparison judgment matrix $\left(U_{I j}\right) 4 \times 4$ can be obtained. $U_{I j}$ represents the importance of indicators of $U_{i}$ and $U_{j}$ for the targets (see judgment matrix in Table 2).

Table 2 Performance target — index layer judgment matrix of engineering teachers in universities

\begin{tabular}{|c|c|c|c|c|}
\hline $\mathrm{U}$ & $\mathrm{U}_{1}$ & $\mathrm{U}_{2}$ & $\mathrm{U}_{3}$ & $\mathrm{U}_{4}$ \\
\hline $\mathrm{U}_{1}$ & $\mathrm{U}_{11}$ & $\mathrm{U}_{12}$ & $\mathrm{U}_{13}$ & $\mathrm{U}_{14}$ \\
\hline $\mathrm{U}_{2}$ & $\mathrm{U}_{21}$ & $\mathrm{U}_{22}$ & $\mathrm{U}_{23}$ & $\mathrm{U}_{24}$ \\
\hline $\mathrm{U}_{3}$ & $\mathrm{U}_{31}$ & $\mathrm{U}_{32}$ & $\mathrm{U}_{33}$ & $\mathrm{U}_{34}$ \\
\hline $\mathrm{U}_{4}$ & $\mathrm{U}_{41}$ & $\mathrm{U}_{42}$ & $\mathrm{U}_{43}$ & $\mathrm{U}_{44}$ \\
\hline
\end{tabular}

Obviously, matrix $\left(\mathrm{U}_{\mathrm{ij}}\right) 4 \times 4$ has the following nature
(1) $\mathrm{U}_{\mathrm{ij}}>0$
(2) $\mathrm{U}_{\mathrm{ij}}=1 / \mathrm{U}_{\mathrm{ji}}(\mathrm{i} \neq \mathrm{j})$
(3) $\mathrm{U}_{\mathrm{ii}}=1 /(\mathrm{I}, \mathrm{j}=1,2,3,4)$

For matrix $\left(U_{I j}\right) 4 \times 4$, if for any $i, j, k$, there is $U_{I j} \cdot U_{j k}=U i k$, the matrix $\left(U_{I j}\right) 4 \times 4$ is the consistent matrix. To determine the specific values of judgment matrix, T.L. Saaty has proposed the scale of 1-9, the meaning is shown in Table 3:

Table 3 Scale of judgment matrix and its meaning

\begin{tabular}{|c|l|c|}
\hline No. & element importance level( $\mathrm{i}$ to $\mathrm{j}$ ) & Uij valuation \\
\hline 1 & i is equally important with $\mathrm{j}$ & 1 \\
\hline 2 & i is a little bit important than $\mathrm{j}$ & 3 \\
\hline 3 & i is obviously important than $\mathrm{j}$ & 5 \\
\hline 4 & i is strongly important than $\mathrm{j}$ & 7 \\
\hline 5 & i is extremely important than $\mathrm{j}$ & 9 \\
\hline 6 & i is a little bit less important than $\mathrm{j}$ & $1 / 3$ \\
\hline 7 & i is obviously less important than $\mathrm{j}$ & $1 / 5$ \\
\hline 8 & i is strongly less important than $\mathrm{j}$ & $1 / 7$ \\
\hline 9 & i is extremely less important than $\mathrm{j}$ & $1 / 9$ \\
\hline
\end{tabular}




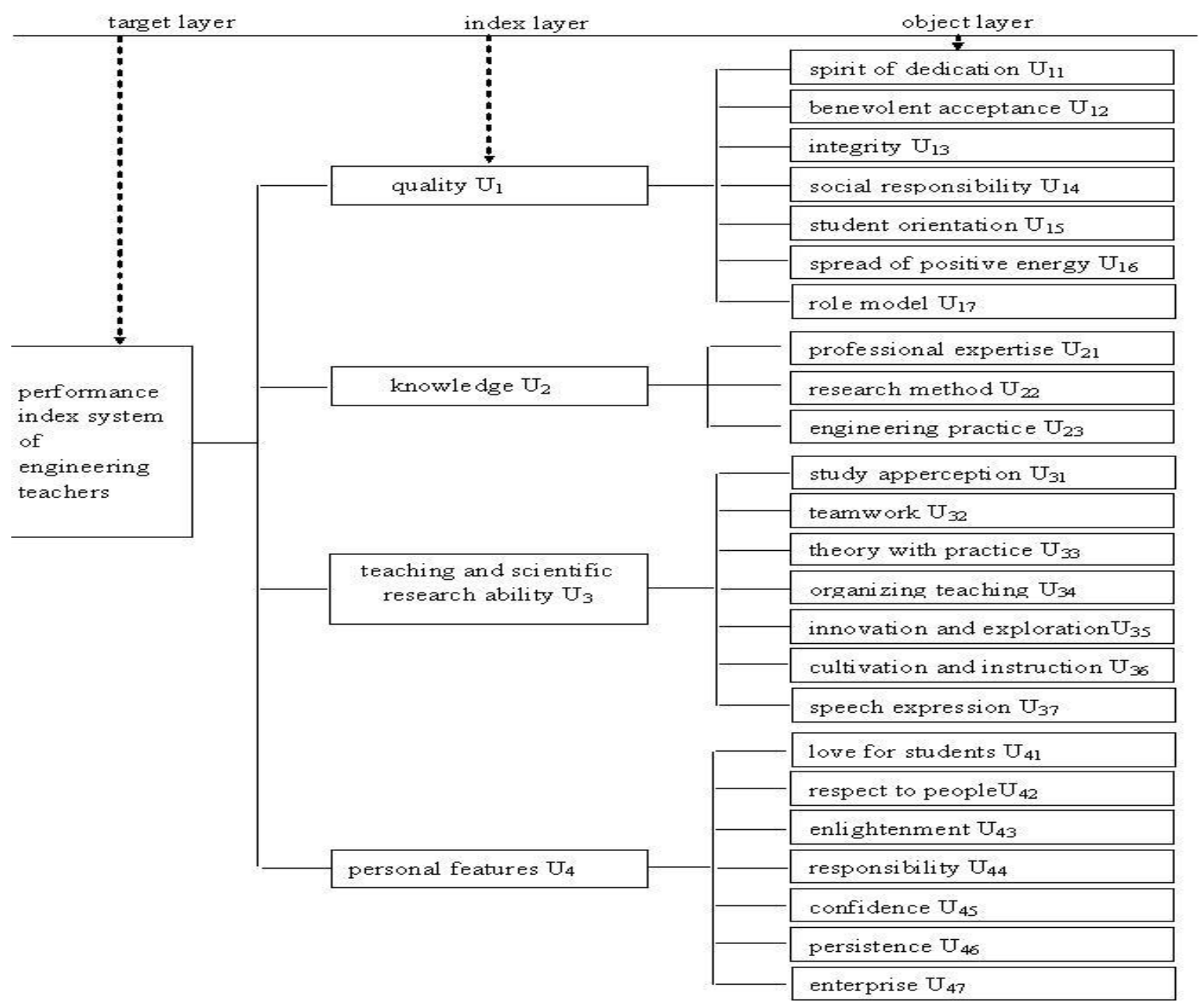

Figure 1. Index system of performance evaluation of engineering teachers in universities

NOTE: $\mathrm{U}$ ij $=\{2,4,6,8,1 / 2,1 / 4,1 / 6,1 / 8\}$ indicates their levels of importance between $\mathrm{U}_{\mathrm{ij}}=\{1,3,5,7,9,1 / 3,1 / 5,1 / 7,1 / 9\}$.

In this paper, the judgment matrix of the layer $U$ of performance objective of engineering teachers in universities for the next layer index layer $\mathrm{U}_{1}, \mathrm{U}_{2}, \mathrm{U}_{3}, \mathrm{U}_{4}$ and the judgment of the matrix of the index layer and the object layer are formed by seven experts who fill in the inquiry forms (see Table 4, Table 5, Table 6, Table7, Table 8).

Consistency Check. Only when the matrix is exactly consistent, there is the presence of the judgment matrix $\lambda 1=\lambda \max =\mathrm{n}$, other latent roots are zero; when judgment matrix is not exactly consistent, $\lambda \max =\mathrm{n}$, other latent roots have the following relationship (see formula 1 ):

Table 4 Judgment matrix of $\mathrm{U}$-index layer $\mathrm{U}_{\mathrm{i}}$ of performance indicator system

\begin{tabular}{|c|c|c|c|c|}
\hline $\mathrm{U}$ & $\mathrm{U}_{1}$ & $\mathrm{U}_{2}$ & $\mathrm{U}_{3}$ & $\mathrm{U}_{4}$ \\
\hline $\mathrm{U}_{1}$ & 1 & $1 / 2$ & 2 & 3 \\
\hline $\mathrm{U}_{2}$ & 2 & 1 & 3 & 4 \\
\hline $\mathrm{U}_{3}$ & $1 / 2$ & $1 / 3$ & 1 & 2 \\
\hline $\mathrm{U}_{4}$ & $1 / 3$ & $1 / 2$ & $1 / 4$ & 1 \\
\hline
\end{tabular}

Table 5 Judgment matrix of U1 - object layer of performance indicator system 


\begin{tabular}{|c|c|c|c|c|c|c|c|}
\hline $\mathrm{U}_{1}$ & $\mathrm{U}_{11}$ & $\mathrm{U}_{12}$ & $\mathrm{U}_{13}$ & $\mathrm{U}_{14}$ & $\mathrm{U}_{15}$ & $\mathrm{U}_{16}$ & $\mathrm{U}_{17}$ \\
\hline $\mathrm{U}_{11}$ & 1 & 1 & $1 / 3$ & $1 / 2$ & 1 & 1 & $1 / 4$ \\
\hline $\mathrm{U}_{12}$ & 1 & 1 & $1 / 3$ & $1 / 2$ & 1 & 1 & $1 / 5$ \\
\hline $\mathrm{U}_{13}$ & 3 & 3 & 1 & 2 & 3 & 3 & $1 / 2$ \\
\hline $\mathrm{U}_{14}$ & 2 & 2 & $1 / 2$ & 1 & 2 & 2 & $1 / 3$ \\
\hline $\mathrm{U}_{15}$ & 1 & 1 & $1 / 3$ & $1 / 2$ & 1 & 1 & $1 / 5$ \\
\hline $\mathrm{U}_{16}$ & 1 & 1 & $1 / 3$ & $1 / 2$ & 1 & 1 & $1 / 6$ \\
\hline $\mathrm{U}_{17}$ & 4 & 5 & 2 & 3 & 5 & 6 & 1 \\
\hline
\end{tabular}

Table 6 Judgment matrix of U2 - object layer of performance indicator system

\begin{tabular}{|c|c|c|c|}
\hline $\mathrm{U}_{2}$ & $\mathrm{U}_{21}$ & $\mathrm{U}_{22}$ & $\mathrm{U}_{23}$ \\
\hline $\mathrm{U}_{21}$ & 1 & $1 / 2$ & 3 \\
\hline $\mathrm{U}_{22}$ & 2 & 1 & 5 \\
\hline $\mathrm{U}_{23}$ & $1 / 5$ & $1 / 3$ & 1 \\
\hline
\end{tabular}

Table 7 Judgment matrix of U3 - object layer of performance indicator system

\begin{tabular}{|c|c|c|c|c|c|c|c|}
\hline $\mathrm{U}_{3}$ & $\mathrm{U}_{31}$ & $\mathrm{U}_{32}$ & $\mathrm{U}_{33}$ & $\mathrm{U}_{34}$ & $\mathrm{U}_{35}$ & $\mathrm{U}_{36}$ & $\mathrm{U}_{37}$ \\
\hline $\mathrm{U}_{31}$ & 1 & $1 / 4$ & $1 / 3$ & 1 & $1 / 3$ & $1 / 3$ & $1 / 6$ \\
\hline $\mathrm{U}_{32}$ & 4 & 1 & 2 & 4 & 2 & 3 & $1 / 2$ \\
\hline $\mathrm{U}_{33}$ & 3 & $1 / 2$ & 1 & 3 & 1 & 2 & $1 / 4$ \\
\hline $\mathrm{U}_{34}$ & 1 & $1 / 4$ & $1 / 2$ & 1 & 2 & $1 / 2$ & $1 / 7$ \\
\hline $\mathrm{U}_{35}$ & 3 & $1 / 2$ & 1 & $1 / 2$ & 1 & 2 & $1 / 3$ \\
\hline $\mathrm{U}_{36}$ & 3 & $1 / 3$ & $1 / 2$ & 2 & $1 / 2$ & 1 & $1 / 5$ \\
\hline $\mathrm{U}_{37}$ & 6 & 2 & 4 & 7 & 3 & 5 & 1 \\
\hline
\end{tabular}

Table 8 Judgment matrix of U4 - object layer of performance indicator system

\begin{tabular}{|c|c|c|c|c|c|c|c|}
\hline $\mathrm{U}_{4}$ & $\mathrm{U}_{41}$ & $\mathrm{U}_{42}$ & $\mathrm{U}_{43}$ & $\mathrm{U}_{44}$ & $\mathrm{U}_{45}$ & $\mathrm{U}_{46}$ & $\mathrm{U}_{47}$ \\
\hline $\mathrm{U}_{41}$ & 1 & 2 & 2 & 1 & 3 & 3 & 2 \\
\hline $\mathrm{U}_{42}$ & $1 / 2$ & 1 & 1 & $1 / 2$ & 2 & 2 & 1 \\
\hline $\mathrm{U}_{43}$ & $1 / 2$ & 1 & 1 & $1 / 2$ & 2 & 2 & 1 \\
\hline $\mathrm{U}_{44}$ & 1 & 2 & 2 & 1 & 3 & 3 & 2 \\
\hline $\mathrm{U}_{45}$ & $1 / 3$ & $1 / 2$ & $1 / 2$ & $1 / 3$ & 1 & 1 & $1 / 2$ \\
\hline $\mathrm{U}_{46}$ & $1 / 3$ & $1 / 2$ & $1 / 3$ & $1 / 3$ & 1 & 1 & $1 / 2$ \\
\hline $\mathrm{U}_{47}$ & $1 / 2$ & 1 & $1 / 3$ & $1 / 2$ & 2 & 2 & 1 \\
\hline
\end{tabular}

$$
\sum_{i=2}^{n} \lambda_{i}=n-\lambda_{\max }
$$

Therefore, the difference $\lambda \max =\mathrm{n}$ can be used to test the degree of coherence. At present, CI (Consistency Index) is used as the consistency index (see formula 2). The smaller the CI is, the greater the consistency is.

$$
C I=\frac{\lambda_{\max }-n}{n-1}
$$

Obviously, for the mutual consistent positive and negative matrix, there is $C I=0, \lambda 1=\lambda$ max $=n$ judgment matrix is completely consistent. But, it is not enough to rely on value CI to judge whether there is consistency check for matrix A, Sometimes the average random consistency index RI needs to be introduced, value $\mathrm{R}$ from band 1 to 9 is shown in Table 9. 
Table 9 Index of average consistency

\begin{tabular}{|c|c|c|c|c|c|c|c|c|c|}
\hline $\mathrm{n}$ & 1 & 2 & 3 & 4 & 5 & 6 & 7 & 8 & 9 \\
\hline $\mathrm{RI}$ & 0 & 0 & 0.58 & 0.90 & 1.12 & 1.24 & 1.32 & 1.41 & 1.45 \\
\hline
\end{tabular}

For 1 and 2 order judgment matrix, RI is only formal. When the order of judgment matrix is greater than 2, the ratio of the judgment matrix consistency index CI to average random consistency index RI of the same order is called consistency ratio, it is referred to as $\mathrm{CR}$. When $\mathrm{CR}=\mathrm{CI} / \mathrm{RI} \leq 0.1$, judge matrix has satisfactory consistency. After calculation, judgment matrix has passed consistency test. Results are shown in Table 10.

Table 10 Calculating results of consistent check

\begin{tabular}{|c|c|c|c|c|}
\hline & CR & $\lambda \max$ & CI & RI \\
\hline target-U & 0.0115 & 4.0310 & 0.0103 & 0.9 \\
\hline quality-U1 & 0.0031 & 7.0247 & 0.0041 & 1.32 \\
\hline knowledge-U2 & 0.0032 & 3.0037 & 0.0018 & 0.58 \\
\hline teaching and scientific research -U3 & 0.0559 & 7.4431 & 0.0739 & 1.32 \\
\hline personal feature-U4 & 0.0026 & 7.0203 & 0.0034 & 1.32 \\
\hline
\end{tabular}

Hierarchical Ordering. Judgment matrix is the calculated basis of AHP, AW $=\lambda$ max $W$ is used to solve $\lambda$ max corresponding feature vector $W$ of $\lambda$ max, which is normalized, namely the weighting coefficient of the corresponding index of the same level for some indicator of the top level. Root method is used in this paper, calculating method are seen in formula (3), formula (4) and (5). The results are in Table 11.

Table 11 Total weight of each element

\begin{tabular}{|c|c|c|c|c|c|}
\hline & 1st level & weight $\mathrm{W}_{\mathrm{i}}$ & 2nd level & stratification weight & total weight $\mathrm{W}_{\mathrm{ij}}$ \\
\hline \multirow{24}{*}{$\mathrm{U}$} & \multirow{7}{*}{$\mathrm{U}_{1}$} & \multirow{7}{*}{0.2776} & $\mathrm{U}_{11}$ & 0.0729 & 0.020237 \\
\hline & & & $\mathrm{U}_{12}$ & 0.0706 & 0.019599 \\
\hline & & & $\mathrm{U}_{13}$ & 0.2151 & 0.059712 \\
\hline & & & $\mathrm{U}_{14}$ & 0.1320 & 0.036643 \\
\hline & & & $\mathrm{U}_{15}$ & 0.0706 & 0.019599 \\
\hline & & & $\mathrm{U}_{16}$ & 0.0688 & 0.019099 \\
\hline & & & $\mathrm{U}_{17}$ & 0.3699 & 0.102684 \\
\hline & \multirow{3}{*}{$\mathrm{U}_{2}$} & \multirow{3}{*}{0.4668} & $\mathrm{U}_{21}$ & 0.3090 & 0.144241 \\
\hline & & & $\mathrm{U}_{22}$ & 0.5816 & 0.271491 \\
\hline & & & $\mathrm{U}_{23}$ & 0.1095 & 0.051115 \\
\hline & \multirow{7}{*}{$\mathrm{U}_{3}$} & \multirow{7}{*}{0.1603} & $\mathrm{U}_{31}$ & 0.0442 & 0.007085 \\
\hline & & & $\mathrm{U}_{32}$ & 0.2139 & 0.034288 \\
\hline & & & $\mathrm{U}_{33}$ & 0.1251 & 0.020054 \\
\hline & & & $\mathrm{U}_{34}$ & 0.0592 & 0.00949 \\
\hline & & & $\mathrm{U}_{35}$ & 0.1009 & 0.016174 \\
\hline & & & $\mathrm{U}_{36}$ & 0.0802 & 0.012856 \\
\hline & & & $\mathrm{U}_{37}$ & 0.3766 & 0.060369 \\
\hline & \multirow{7}{*}{$\mathrm{U}_{4}$} & \multirow{7}{*}{0.0953} & $\mathrm{U}_{41}$ & 0.2371 & 0.022596 \\
\hline & & & $\mathrm{U}_{42}$ & 0.1287 & 0.012265 \\
\hline & & & $\mathrm{U}_{43}$ & 0.1287 & 0.012265 \\
\hline & & & $\mathrm{U}_{44}$ & 0.2371 & 0.022596 \\
\hline & & & $\mathrm{U}_{45}$ & 0.0699 & 0.006661 \\
\hline & & & $\mathrm{U}_{46}$ & 0.0699 & 0.006661 \\
\hline & & & $\mathrm{U}_{47}$ & 0.1287 & 0.012265 \\
\hline
\end{tabular}

(1)To calculate the product $\mathrm{M}_{\mathrm{i}}$ of the elements of each row of judgment matrix 
$M_{i}=\prod_{j=1}^{n} a_{i j}(i=1,2, \cdots, n)$

(2) To calculate n-th root $\overline{\mathrm{W}}_{\mathrm{I}}$ of $\overline{\mathrm{W}}_{\mathrm{I}}$

$$
\overline{W_{i}}=\sqrt[n]{M_{i}}
$$

(3) To normalize the vector $\overline{\mathrm{W}}=\overline{\mathrm{W}}_{1}, \overline{\mathrm{W}}_{2}, \ldots, \overline{\mathrm{W}} \mathrm{n}^{\mathrm{T}}$

$$
W_{i}=\overline{W_{i}} / \sum_{j=1}^{n} \overline{W_{j}}
$$

Therefore, $\mathrm{W}=\mathrm{W}_{1}, \mathrm{~W}_{2}, \ldots, \mathrm{W}_{\mathrm{n}}^{\mathrm{T}}$ is the feature vector of seeking weight.

Therefore weight vector of a set of elements for some element on a topper layer is obtained and finally sequence weight of the various elements of the level of the lowest program for the target is gained. Thereby, selection of program is conducted. The calculation of the total weight is composed from the top down in accordance with a single criterion.

In order to facilitate research, only part of the data of the questionnaire of competency evaluation is selected in W University. We select 34 questionnaires of self-evaluation of engineering teachers as samples and calculate the results according to the weight determined in Table11. Results are shown in Table 12.

\section{Summary}

In accordance with the developing stages and strategies of the universities participating in the plan of PETOE, it is of great importance to reasonably determine the index of performance evaluation of engineering teachers to promote the implementation of the plan of PETOE. Performance evaluation of engineering teachers should aim at improving teachers' competence level as a starting point, and that is the reason why index framework of performance evaluation is distinguished from the previous research to take competency theory of iceberg model as the theoretical basis and apply analytic hierarchy process (AHP) to determine the index weight to evaluate the performance level of engineering teachers.

In a nutshell, AHP is good at expressing subjective judgment of the people in the form of numbers. Weights are determined by the means of AHP which is used to obtain rough quantitative evaluations in pairwise comparison on the basis of professional knowledge and subjective experience. After that, the rationality of the weight is tested according to the judgment whether there is satisfactory consistency for a matrix to make the weigh more objective and simple to be quantified. In brief, there are advantages of clear implementation step, simple judgment rule, quantitative indicators as well as operable data processing section for the Analytic Hierarchy Process (AHP).Thus the reliability and accuracy of the performance evaluation can be improved. 
Table 12 Results of performance evaluation of AHP of engineering teachers in W university

\begin{tabular}{|c|c|c|c|c|c|}
\hline No. & sex & age & title & $\begin{array}{c}\text { score } \\
\text { of evaluation }\end{array}$ & percentile Score \\
\hline ZP001 & Male & 38 & lecturer & 8.171236 & 90.79151 \\
\hline ZP002 & Male & 53 & associate professor & 8.057526 & 89.52807 \\
\hline ZP003 & Male & 46 & associate professor & 8.051344 & 89.45938 \\
\hline ZP004 & Male & 36 & lecturer & 8.384824 & 93.16471 \\
\hline ZP005 & Male & 39 & associate Professor & 7.957929 & 88.42143 \\
\hline ZP006 & Male & 36 & lecturer & 8.261267 & 91.79186 \\
\hline ZP007 & Male & 35 & lecturer & 8.625388 & 95.83764 \\
\hline ZP008 & Male & 36 & associate professor & 7.031283 & 78.12537 \\
\hline ZP009 & Male & 38 & associate professor & 7.072217 & 78.58019 \\
\hline ZP010 & Male & 45 & professor & 8.247954 & 91.64393 \\
\hline ZP011 & Male & 32 & lecturer & 7.214198 & 80.15776 \\
\hline ZP012 & Male & 43 & professor & 7.595864 & 84.39849 \\
\hline ZP013 & Male & 48 & professor & 8.536483 & 94.84981 \\
\hline ZP014 & Male & 44 & associate professor & 7.567526 & 84.08362 \\
\hline ZP015 & Male & 31 & lecturer & 8.492185 & 94.35761 \\
\hline ZP016 & Male & 53 & associate professor & 8.385913 & 93.17681 \\
\hline ZP017 & Male & 55 & professor & 7.743958 & 86.04398 \\
\hline ZP018 & Male & 38 & associate professor & 8.560462 & 95.11624 \\
\hline ZP019 & Male & 44 & professor & 7.810079 & 86.77866 \\
\hline ZP020 & Male & 48 & associate professor & 8.185521 & 90.95023 \\
\hline ZP021 & Male & 36 & lecturer & 8.419903 & 93.55448 \\
\hline $\mathrm{ZP022}$ & Female & 35 & lecturer & 8.610484 & 95.67204 \\
\hline $\mathrm{ZP} 023$ & Female & 48 & professor & 7.95943 & 88.43811 \\
\hline ZP024 & Female & 33 & assistant & 8.210952 & 91.2328 \\
\hline ZP025 & Female & 32 & lecturer & 7.241441 & 80.46046 \\
\hline ZP026 & Female & 44 & associate professor & 8.124543 & 90.2727 \\
\hline $\mathrm{ZP} 027$ & Female & 36 & assistant & 8.378991 & 93.0999 \\
\hline ZP028 & Female & 32 & assistant & 8.476565 & 94.18406 \\
\hline ZP029 & Female & 58 & professor & 7.827661 & 86.97401 \\
\hline ZP030 & Female & 33 & lecturer & 7.982569 & 88.69521 \\
\hline ZP031 & Female & 34 & assistant & 7.996101 & 88.84557 \\
\hline ZP032 & Female & 40 & associate Professor & 8.16841 & 90.76011 \\
\hline ZP033 & Female & 37 & lecturer & 7.610157 & 84.5573 \\
\hline ZP034 & Female & 34 & assistant & 8.007975 & 88.9775 \\
\hline
\end{tabular}

\section{References}

[1] Tai Sik Lee, Du-Hwan Kim, Dong Wook Lee et al. A competency model for project construction team and project control Team [J]. KSCE Journal of Civil Engineering, 2011, 15(5): 781-792.

[2] McClelland D C. Testing for competence rather than for intelligence [J]. American Psychologist, 1973, vol (28): 1-14.

[3] McClelland D C. Identifying competencies with behavioral event interviews [J]. Psychological Science, 1998, 9: 331-339.

[4] Yoshitaka Yamazaki. Using a competency approach to understand host-country national managers in Asia [J]. The International Journal of Human Resource Management, 2014, 
25(15/16): 2103-2128.

[5] Anabel Fernandez-Mesa, Jose Luis Ferreras-Mendez, Joaquin Alegre et al. IT competency and the commercial Success of innovation [J]. Industrial Management \& Data Systems, 2014, 114(4):550-567.

[6] T.L.Saaty. Decision-making with the AHP: Why is the principal eigenvector necessary [J]. European Journal of Operational Research, 2003, 145: 85- 91.

[7] Lewis. Understanding human competence at work: an interpretative approach [J]. Academy of Management Journal, 2014, (3):43.

[8] Morrison. Enhancing professional practice: A Framework for teaching [J].Alexandr VA 2012, (51):4-5.

[9] Qin Liang-sheng. Analysis of the application of 360-degree feedback to the teachers' performance evaluation in universities [J]. Chinese Adult Education, 2007, (9).

[10] Guo Cai-qin, Zhang Zheng-yi. Application of balanced score card to performance evaluation of teachers in chinese universities [J]. Journal of Chang zhi College, 2006, (1).

[11]Xu Cheng-peng. Performance evaluation of teachers in universities based on analytic hierarchy process and fuzzy mathematics method [J]. Hei Long-jiang Education (Higher Educational Research and Evaluation), 2007 (3).

[12]Zhu Cui-miao. Exploration of the rules of Performance Evaluation of Teachers in Universities Based on Rough Set [J].Technological Square, 2007, (3).

[13] Su Ning-hong. AHP method of Performance Evaluation of Teachers in Universities [J]. Educational Research in Jiangxi, 2007, (4).

[14]Chen Shao-hui. Research on the system of the performance evaluation of teachers in local universities in Jilin Province [D].Changchun: Northeast Normal University, 2012.

[15]T.L. Saaty. The Analytic Hierarchy Process [M] .New York: McGraw- Hill International Book Company, 1980.

[16] Sharron A. Frillman, Kari L. Wilde, Jonathan F. Kochert et al. entry-level engineering professionals and product lifecycle management: a competency model [J]. International Journal of Manufacturing Technology and Management, 2013, 19(3/4): 306-311.

[17]Parry S B. Just what is a competency? And why should you care?[J].Training, 2009, (6): 58-64.

[18]Herbert. Response to reexamining Professional Certification in Human Resource Managed by Carolyn Wiley[J].Human Resource Management,2015,34(2):295-297. 